\title{
Phage particles do not communicate with each other or make decisions to either lyse or lysogenize their host cells
}

\author{
M. H. V. Van Regenmortel ${ }^{1}$
}

Received: 7 April 2017/Accepted: 7 April 2017/Published online: 3 May 2017

(C) Springer-Verlag Wien 2017

In a recent paper published in Nature, the sensational claim was made that phage particles of the SPbeta group are able to communicate with each other by allegedly producing an hexapeptide that is released in the culture medium [3]. Progeny phages were said to be able to measure the concentration of this peptide and if the concentration was sufficiently high, the phages would decide to lysogenize their bacterial host cells instead of killing them by lysis. It was suggested that the phages decided to switch into lysogeny because it preserved their capacity to reproduce at a later stage.

In an accompanying News and Views article [1] it was emphasized that these metaphoric interpretations of phage activity demonstrated the remarkable ability of phages to communicate with one another and to decide not to kill their host cells but to opt for the alternative lysogeny cycle.

In several editions of their book Principles of Virology: Pathogenicity and Control, Flint et al. [4] recommended that virologists should refrain from using anthropomorphic metaphors for describing the properties and activities of viruses. It is widely accepted that viruses cannot think, synthesize, create, measure or decide anything because they are passive agents totally at the mercy of their environments. The currently fashionable belief that viruses are living entities is partly due to the willingness of some virologists to attribute to viruses a metaphoric capacity of intentional, goal-directed behaviour [8]. It is equally inappropriate to suggest that phages communicate with each other and make beneficial decisions because they

M. H. V. Van Regenmortel

vanregen@unistra.fr

1 Ecole Superieure de Biotechnologie de Strasbourg, Illkirch, France want to continue to exist in the future. Such metaphors certainly do not give us a meaningful scientific understanding of viral properties and activities.

The original aim of the Erez et al. study [3] was to investigate whether Bacillus subtilis bacteria infected with the phi3T phage were able to secrete peptides that would alert other B subtilis cells to the impending likelihood of phage infection, which would allow these cells to choose the lysogenic option and avoid the deadly lytic cycle. When it was found that the infected bacteria did produce a signalling hexapeptide, the authors ascribed its synthesis to the infecting phage, assuming that viruses synthesize peptides in order to communicate with other virus particles ! The authors concluded that "the signalling hexapeptide was "produced" by the phage" and they gave it the name arbitrium. When phi3T phage particles detect a certain amount of arbitrium in the environment, it was assumed that the phages make the decision to either go on killing their bacterial hosts by lysing them, or alternatively decide to keep them alive by promoting the phage's lysogenic life cycle, giving the phages a chance to survive in the future [3].

Such a scenario may seem extravagant to many virologists because they do not believe that viruses make decisions or self-replicate themselves; they accept that viruses are passively replicated by the metabolic activities of the cells they have infected and that they should not be said to survive since they are actually not living [8]. It seems, indeed, unlikely that inert, non-living phages would intentionally choose the lysogenic option when encountering a potential host because they realize that it gives them a higher probability of surviving.

There is, in fact, a simpler explanation for these observations. Gram-positive bacteria such as B. subtilis possess quorum sensing receptors that allow them to specifically 
detect the presence of certain short peptides in the environment $[1,3]$. When an increased amount of arbitrium released from bacteria infected with phi3T phages is detected by such bacterial receptors, it can lead to novel transcriptional responses in $B$ subtilis cells which promote the lysogenic instead of the lytic cycle [3]. This "advantageous" outcome for the bacteria is simply the result of Darwinian natural selection which preserves the living lysogenized cells and allows the killed, lysed cells to be eliminated. All living organisms are fashioned or shaped by blind evolutionary selection pressures and there is no need to invoke intentionality and purpose to explain such events [7] nor to attribute the survival of $B$ subtilis cells to the fact that the bacteria want to survive and therefore opt for the lysogeny life cycle. It is of course even less justified to attribute such intentions and goals to non-living viruses since this perpetuates the unscientific mental habit of supposing that all objects and events have purposes [5, 8]. In her book, Who Wrote the Book of Life, Lily Kay [6] denounced the many misleading metaphors of codes, messengers and recipients that are prevalent in molecular biology. She pointed out that genetic information has no literal meaning, the codes have no language, the messages have no sender and "the book of life" is devoid of authorship. Although metaphors can be appealing and may have some value as epistemic devices, they do not tell us how the world actually is and they should be avoided since they do not give us a valid scientific understanding $[2,8]$.

\section{References}

1. Davidson AR (2017) Virology: Phages make a group decision. Nature 541:466-467

2. De Donato Rodriguez X, Arroyo-Santos A (2011) The function of scientific metaphors: An example of the creative power of metaphors in biological theories. In Castro S \& Marcos A (Eds.) Nature, science and the arts: vol. 9. The paths of creation. Creativity in science and art (pp. 81e96). Bern: Peter Lang Publishing Group

3. Erez Z, Steinberger-Levy I, Shamir M, Doron S, Stokar-Avihail A et al (2017) Communication between viruses guides lysis-lysogeny decisions. Nature 541:488-493

4. Flint SJ, Enquist LW, Racaniello VR (2009) Principles of virology: pathogenesis and control (3rd ed.). ASM Press, Washington DC

5. Hanke D (2004) In: Cornwell J (ed) Explanations. styles of explanation in science, Oxford University Press, Oxford, pp $143-155$

6. Kay L (2000) Who Wrote the book of life? A history of the genetic code. Stanford University Press, Stanford

7. Van Regenmortel MHV (2007) The rational design of biological complexity: a deceptive metaphor. Proteomics 7:965-975

8. Van Regenmortel MHV (2016) The metaphor that viruses are living is alive and well, but it is no more than a metaphor. Stud Hist Phil Biol Biomed Sci 59:117-125 